\title{
Oral immunization with Lactococcus lactis-expressing EspB induces protective immune responses against Escherichia coli 0157:H7 in a murine model of colonization
}

\author{
B. Ahmed ${ }^{\mathrm{a}}$, M. Loos ${ }^{\mathrm{a}}$, D. Vanrompay ${ }^{\mathrm{b}}$, E. Cox ${ }^{\mathrm{a}, *}$ \\ a Laboratory of Immunology, Faculty of Veterinary Medicine, Ghent University, Salisburylaan 133, B-9820 Merelbeke, Belgium \\ b Department of Molecular Biotechnology, Faculty of Bioscience Engineering, Ghent University, Coupure Links 653, B-9000 Gent, Belgium
}

\section{A R T I C L E I N F O}

\section{Article history:}

Received 27 February 2014

Received in revised form 1 May 2014

Accepted 15 May 2014

Available online 28 May 2014

\section{Keywords:}

Lactococcus lactis

Enterohemorrhagic Escherichia coli

Hemolytic uremic syndrome

EspB

Oral vaccination

\begin{abstract}
A B S T R A C T
Enterohemorrhagic Escherichia coli (EHEC) have been responsible for several outbreaks of hemolytic-uremic syndrome (HUS) worldwide. HUS is the most common cause of acute renal failure in children and results in fatalities as high as $50 \%$ in the elderly. Currently, neither a specific treatment nor a vaccine is available for EHEC. Lactococcus lactis is a generally regarded as safe "GRAS" bacterium that offers a valuable platform for oral vaccine delivery. Toward the development of an oral vaccine against EHEC, we have previously constructed a recombinant $L$. lactis strain expressing the EHEC antigen, EspB in the cytoplasmic compartment. However, oral immunization of mice with this strain induced weak priming of the immune system. This outcome was attributed to the rather low levels of EspB expressed by this recombinant strain. Therefore, in the present study we optimized the expression of $\mathrm{EspB}$ in L. lactis by secreting the antigen either under constitutive or nisin-inducible control. Indeed, oral immunization of mice with the EspB-secreting strains successfully induced specific mucosal and systemic antibody responses. These responses were associated with mixed Th1/Th2 cell responses in Peyer's Patches and mesenteric lymph nodes. Moreover, immunized mice exhibited significant protection against E. coli 0157:H7 colonization, as indicated by the reduced amount and/or duration of the bacterial fecal shedding. Our results demonstrate the protective potential of EspB as an oral vaccine against EHEC infection. Additionally, the study demonstrates the efficient delivery of recombinant EspB by the "GRAS" bacterium, L. lactis. The safety profile of $L$. lactis as a vaccine vehicle can particularly be beneficial to children and elderly as high-risk groups for HUS incidence.
\end{abstract}

(C) 2014 Elsevier Ltd. All rights reserved.

\section{Introduction}

Enterohemorrhagic Escherichia coli (EHEC) is one group of colonizing enteropathogens that has been responsible for frequent outbreaks of diarrhea and hemorrhagic colitis (HC) worldwide [1]. HC occasionally progresses to hemolytic-uremic syndrome (HUS), which is the most common cause of acute renal failure in children [2] and results in fatality rates as high as $50 \%$ in the elderly [3]. HC and HUS are caused by shiga-like toxins (Stxs), which are released by colonizing EHEC into the systemic circulation and induce endothelial damage in intestinal and renal vasculatures [4]. Several studies have linked antibiotic therapy to higher rates of HUS development and prolonged duration of the symptomatic disease, probably due to the excessive release of Stxs upon bacterial

\footnotetext{
* Corresponding author. Tel.: +32 4834 32240; fax: +32 92647797

E-mail address: Eric.Cox@UGent.be (E.Cox).
}

lysis [3,5-7]. Therefore, current disease intervention strategies are rather focusing on vaccination. However, no vaccine is currently available for EHEC infections.

Since the Stxs-mediated EHEC diseases develop subsequent to the bacterial intestinal colonization, the latter is considered a key determinant of EHEC pathogenicity and represents a potential target for vaccine design. EHEC colonizes the intestine with the aid of a type III secretion system (T3SS) which enables the bacteria to establish a tight adherence to enterocytes and to modify their cytoskeletal proteins, leading to the characteristic attaching and effacing lesion [8]. EspB is a T3SS protein that plays a central role in mediating the EHEC enterocyte adherence [8-12]. Moreover, EspB is highly immunogenic in human patients [13-15] and in infected or vaccinated animals $[13,16]$. Therefore, EspB is a potential candidate antigen for vaccination against EHEC.

Oral vaccination can be a particularly efficient approach to interfere with EHEC intestinal colonization, as it can effectively induce local immune responses at the intestinal mucosa, and 
concurrently elicit systemic immune responses [17]. Nevertheless, oral vaccines are at the risk of being degraded by the harsh gastrointestinal conditions. Thus, vaccine delivery systems represent a useful strategy to ensure the efficient oral delivery of antigens $[18,19]$. One of the interesting oral antigen delivery systems is based on genetically modified lactic acid bacteria (LAB) that simultaneously express and deliver antigens to the intestinal mucosa $[20,21]$. LAB have been traditionally used in food industry and are generally regarded as safe "GRAS" for human consumption. Therefore, they particularly offer a safe tool for the oral delivery of vaccines. Lactococcus lactis is a model LAB that has been extensively studied for oral vaccine delivery. Numerous bacterial, viral and parasitic antigens were expressed in L. lactis and the resultant recombinant strains were capable of inducing specific mucosal and systemic immune responses in mice upon oral administration (for a recent review, [22]). We have recently reported the constitutive cytoplasmic expression of EspB in L. lactis [23]. However, oral immunization of mice using this recombinant strain induced weak priming of the immune system. This outcome was attributed to the low levels of EspB expressed by this strain [23].

In the present study, we describe the optimized expression of EspB in L. lactis. Additionally, we describe the specific immune responses elicited in mice upon oral immunization with the recombinant strains and the protection conferred against a challenge infection with E. coli 0157:H7.

\section{Materials and methods}

\subsection{Bacteria, plasmids and culture conditions}

A summary of the bacterial strains and plasmids used in this study is shown in Table 1. L. lactis was grown at $30^{\circ} \mathrm{C}$ in liquid M17 medium (Difco) supplemented with $0.5 \%$ glucose. Erythromycin or chloramphenicol was added at concentrations of 5 and $10 \mu \mathrm{g} / \mathrm{ml}$, respectively. E. coli NCTC12900 was grown at $37^{\circ} \mathrm{C}$ in Luria-Bertani broth (Difco) supplemented with 80,15 and $100 \mu \mathrm{g} / \mathrm{ml}$ of novobiocin, naladixic acid and streptomycin, respectively.

\subsection{Constructions of the EspB-expressing L. lactis strains}

Plasmids pT:SEC-EspB and pNZ:SEC-EspB were constructed for constitutive or nisin-inducible secretion of EspB, respectively (Table 1 and Fig. 1). For construction of plasmid pT:SEC-EspB, the espB gene was PCR amplified from plasmid pT:CYT-EspB [23] using sequence-specific primer pairs (forward: 5'-GGGGGATCCAACACTATCGATAACACTCAAG-3'; reverse: 5'-GGGACTAGTTTAACCAGCAA GACG-3'). pT:CYT-EspB carries a codon optimized espB gene of E. coli 0157:H7 (Genbank Accession no: NC_002655), adapted to the preferential codon use of $L$. lactis [23]. The amplified espB gene was inserted downstream of the secretion signal peptide $\mathrm{SP}_{\mathrm{Usp} 45}$ at the BamHI/SpeI ends of pTREX1 (Fig. 1). For the construction of plasmid pNZ:SEC-EspB, espB along with $\mathrm{SP}_{\mathrm{Usp} 45}\left(\mathrm{SP}_{U s p 45}-\mathrm{espB}\right)$ was PCR amplified from $\mathrm{pT}$ :SEC-EspB using sequence-specific primer pairs (forward: 5'-ATGAAAAAAAAGATTATCTCAGC-3'; reverse: 5'GGGACTAGTTTAACCAGCAAGACG-3') and was inserted at the Scal/Spel ends of plasmid pNZ8150 (Fig. 1). Plasmids pT:SEC-EspB and pNZ:SEC-EspB were used to transform electrocompetent $L$. lactis MG1363 and L. lactis NZ9000 [24] to obtain the recombinant strains LL-pT:SEC-EspB and LL-pNZ:SEC-EspB, respectively (Table 1).

\subsection{Induction and quantification of EspB expression in L. lactis}

Overnight cultures of the inducible LL-pNZ:SEC:EspB strain or the constitutive, LL-pT:CYT:EspB and LL-pT:SEC:EspB strains were inoculated in GM17 broth at dilutions of 1:25 and 1:100, respectively. All strains were grown to an optical density at $600 \mathrm{~nm}$ of 0.4 , at which, nisin $(10 \mathrm{ng} / \mathrm{ml})$ was added to the culture medium of LL-pNZ:SEC:EspB. LL-pT:CYT:EspB and LL-pT:SEC:EspB cells were harvested by centrifugation and resuspended in buffered-GM9 (BGM9) medium [25]. After a further $4 \mathrm{~h}$ incubation, cells or supernatant of equal culture volumes were collected for each strain. L. lactis cell lysates were enzymatically obtained as previously described [23]. EspB was detected and quantified in cell lysates and supernatants of the L. lactis cultures using a specific sandwich ELISA, as previously described [23].

\subsection{Oral immunization of mice with the EspB-expressing L. lactis strains}

Six-week-old female BALB/c mice were used in the animal experiments. All experimental and animal management procedures were approved by the animal care and ethics committee of Ghent University, Belgium. The lactococcal strains were grown and induced as described above. Cells of the inducible strains were washed twice with sterile PBS to remove the traces of nisin. Groups of nine mice were immunized orally with LL-pT:SEC:EspB, LL-pNZ:SEC:EspB, purified EspB, LL-pTREX1, LL-pNZ8150 or the inoculation medium BGM9 [25]. As a primary immunization mice received $100 \mu \mathrm{l}$ of BGM9 containing $2 \times 10^{9} \mathrm{CFU}$ of the proper lactococcal strain or $5 \mu \mathrm{g}$ of purified EspB for three consecutive days. A booster immunization was performed three weeks later using the same regime.

\subsection{EspB-specific antibodies}

Total serum EspB-specific immunoglobulins (total-Ig) and faecal IgA were measured 10 days after the booster immunization. Preparation of serum and fecal extracts as well as the ELISA procedures were performed as previously described [23]. The ELISA results are expressed as the OD values measured at $405 \mathrm{~nm}$ for dilutions of $1: 10$ for serum and $1: 5$ for fecal extracts.

\subsection{Cytokine ELISA's}

Peyer's patches (PP) and mesenteric lymph node (MLN) lymphocytes were isolated from immunized mice $(n=3), 10$ days after the booster immunization. Cells were resuspended at a concentration of $1.5 \times 10^{6}$ cells $/ \mathrm{ml}$ in complete RPMI-1640 medium [26] and cultured in 96-well plates. Cells were restimulated with EspB (final concentration: $10 \mu \mathrm{g} / \mathrm{ml}$ ) for $48 \mathrm{~h}$. Thereafter, supernatants were collected and assayed for murine INF- $\gamma$, IL- 4 and IL- 10 by quantitative ELISA using the mouse Th1/Th2 ELISA Ready-SET-Go ${ }^{\circledR}$ kit (eBioscience), according to the manufacturer's instructions.

\subsection{Challenge with E. coli $0157: H 7$}

Groups of seven mice were immunized as described above. Ten days after the booster immunization, mice of each group were randomly divided into two subgroups, of which, one subgroup $(n=4)$ received streptomycin ( $5 \mathrm{~g} / \mathrm{l})$ in drinking water $24 \mathrm{~h}$ before infection and till the end of the experiment, while the other subgroup $(n=3)$ was not treated with streptomycin. These subgroups represent two models of varying colonization intensities, since streptomycin treatment enhances EHEC colonization in mice by clearing the competing intestinal flora [27]. Mice were challenged by intragastric inoculation of $10^{10}$ CFU of E. coli NCTC12900 in $100 \mu$ l of PBS containing 20\% sucrose. Faecal excretion of E. coli NCTC12900 was monitored at 2-3 days interval, by both conventional bacterial plating and immuno-magnetic separation, as previously described [28]. 
Table 1

Bacterial strains and plasmid vectors.

\begin{tabular}{|c|c|c|}
\hline Plasmid or strain & Description & Reference \\
\hline L. lactis subsp. cremoris MG1363 & A derivative of the dairy starter strain NCDO712, which was cured of all resident plasmids & [61] \\
\hline L. lactis NZ9000 & L. lactis subspecies cremoris MG1363 carrying nisR and nisK genes on the chromosome & [62] \\
\hline LL-pTREX & L. lactis subspecies cremoris MG1363 carrying plasmid pTREX & [23] \\
\hline LL-pNZ8150 & L. lactis NZ9000 carrying plasmid pNZ8150 & This study \\
\hline LL-pT:SEC:EspB & L. lactis subspecies cremoris MG1363 carrying plasmid pT:SEC:EspB & This study \\
\hline LL-pNZ:SEC:EspB & L. lactis NZ9000 carrying plasmid pNZ:SEC:EspB & This study \\
\hline E. coli NCTC12900 & Shiga toxin-negative mutant of E. coli O157:H7, Nov $^{\mathrm{R}}, \mathrm{Nal}^{\mathrm{R}}$ and $\mathrm{Str}^{\mathrm{R}}$ & [63] \\
\hline pTREX1 & L. lactis expression plasmid containing P1 promoter with downstream start codon and secretion signal $\left(\mathrm{SP}_{\mathrm{Usp} 45}\right), \mathrm{Em}^{\mathrm{R}}$ & [46] \\
\hline pNZ8150 & L. lactis expression plasmid containing PnisA promoter with downstream start codon, $\mathrm{Cm}^{\mathrm{R}}$ & [64] \\
\hline pT:CYT:EspB & Modified pTREX1 containing $\mathrm{P}_{1}$ promoter with downstream $\operatorname{esp} B$ gene, $\mathrm{Em}^{\mathrm{R}}$ & [23] \\
\hline pT:SEC:EspB & Modified pTREX1 containing $\mathrm{P}_{1}$ promoter with downstream secretion signal ( $\left.\mathrm{SP}_{\mathrm{Usp}} 45\right)$ and $\operatorname{esp} B, \mathrm{Em}^{\mathrm{R}}$ & This study \\
\hline pNZ:SEC:EspB & Modified pNZ8150 containing PnisA promoter with downstream secretion signal $\left(\mathrm{SP}_{\mathrm{Usp} 45}\right)$ and $\operatorname{espB}, \mathrm{Cm}^{\mathrm{R}}$ & This study \\
\hline
\end{tabular}

$\mathrm{Nal}^{\mathrm{R}}, \mathrm{Str}^{\mathrm{R}}, \mathrm{Cm}^{\mathrm{R}}, \mathrm{Em}^{\mathrm{R}}$ is resistance against naladixic acid, streptomycin, chloramphenicol and erythromycin, respectively.

\subsection{Statistical analyses}

Statistical analyses were performed using GraphPad Prism 6 software (GraphPad Software Inc.). One-way analysis of variance (ANOVA) with Bonferroni post-hoc test was used to analyze the differences in EspB expression levels among the strains as well as the differences in antibody titers, cytokine ratios and duration of fecal shedding among the groups. Pair-wise comparison of individual cytokine levels among immunized and control groups were analyzed using Student's t-test. Two-way ANOVA with Bonferroni
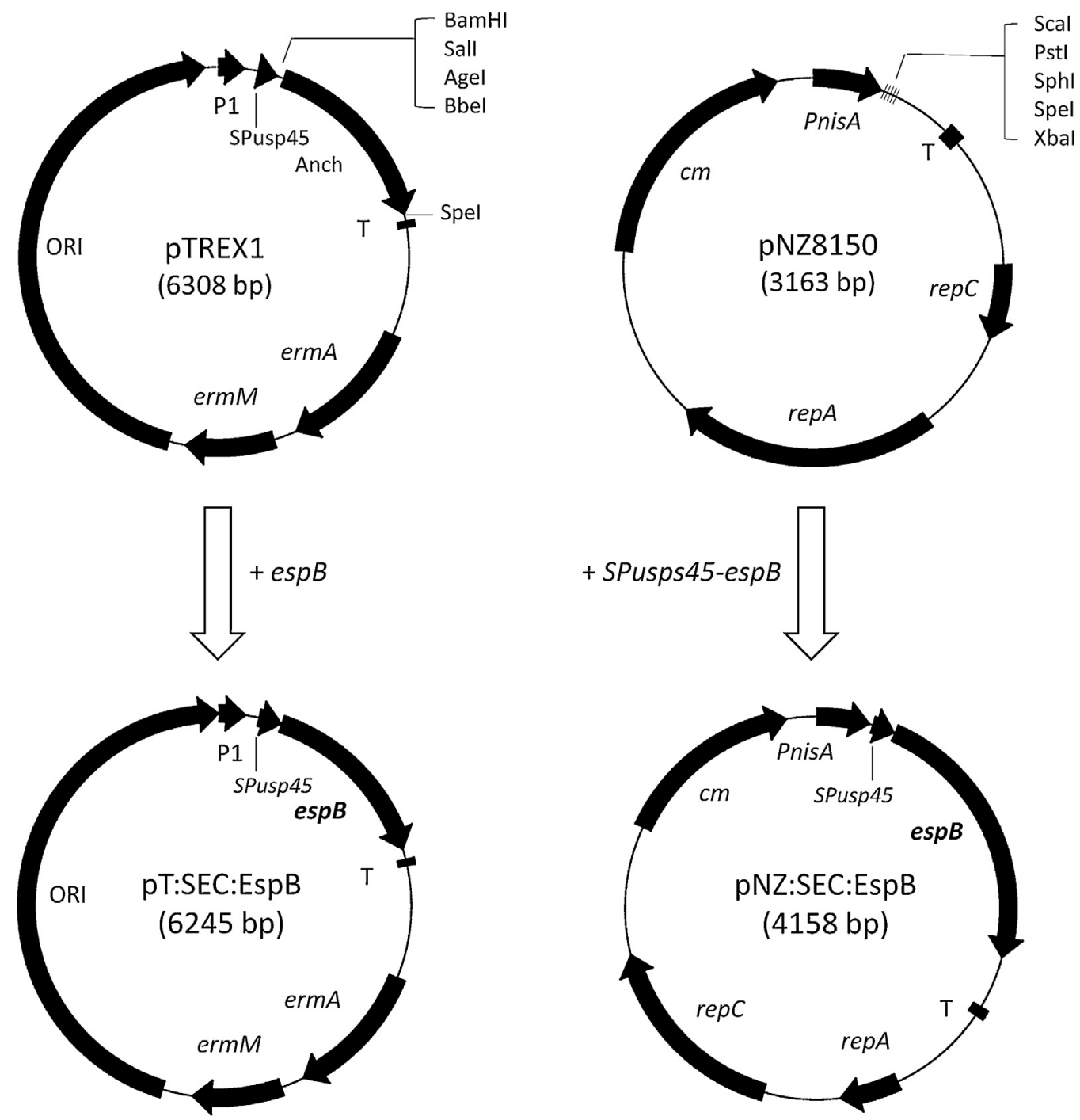

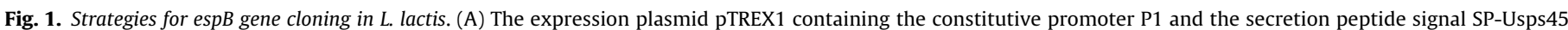

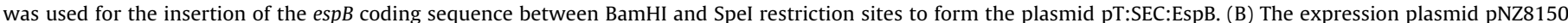

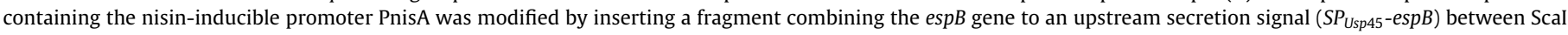
and SpeI restriction sites to form the plasmid pNZ:SEC:EspB. 
post-hoc test was used to analyze the differences in fecal loads of E. coli NCTC12900 over time among the groups. Differences with a $P<0.05$ were considered statistically significant.

\section{Results}

3.1. ELISA quantification of EspB expression by the recombinant $L$. lactis strains

EspB was detected only in the cell lysate of LL-pT:CYT:EspB, while it was detected in both cell lysates and supernatants of LLpNZ:SEC:EspB and LL-pT:SEC:EspB (Table 2). The detection of EspB in cell lysates of the EspB-secreting strains corresponds to the presence of the cytoplasmic precursor of the mature (secreted) protein. The total amount of EspB expressed by the secreting strains LLpNZ:SEC:EspB and LL-pT:SEC:EspB (both cytoplasmic and secreted) was, respectively, 56- and 25-fold higher than that expressed by the cytoplasmic expression strain LL-pT:CYT:EspB $(P<0.05)$. The nisin-inducible LL-pNZ:SEC:EspB strain showed a 2.2-fold higher total EspB expression than the constitutive LL-pT:SEC:EspB strain $(P<0.05)$ (Table 2). Both LL-pNZ:SEC:EspB and LL-pT:SEC:EspB were used for the immunization experiments.

\subsection{EspB-secreting L. lactis strains induce specific antibody responses after oral administration to mice}

Mice orally immunized with either LL-pNZ:SEC:EspB or LLpT:SEC:EspB showed significantly higher levels of EspB-specific serum total-Ig $(P<0.0001)$ and faecal IgA $(P<0.0001)$ compared to those immunized with the corresponding control strains, LL-pNZ8150 and LL-pTREX1, respectively (Fig. 2). The highest antibody responses were elicited by the nisin-inducible strain LLpNZ:SEC:EspB compared to the constitutive strain LL-pT:SEC:EspB $(P<0.0001)$. Mice immunized with purified EspB showed no significant difference in total serum Ig and faecal IgA compared to those receiving the BGM9 medium.

\subsection{Oral immunization with L. lactis-secreting EspB induces mixed Th1/Th2 immune response}

To characterize the cellular immune responses induced by the oral immunization with the EspB-secreting L. lactis strains, the production of INF- $\gamma$ (Th1 cytokine), IL-4 (Th2 cytokine) [29] and IL-10 (a broadly expressed anti-inflammatory cytokine) $[29,30]$ was measured in PP (Fig. 3A) and MLN (Fig. 3C) lymphocytes after in vitro restimulation with EspB. Lymphocytes of both LL-pT:SEC:EspB and LL-pNZ:SEC:EspB immunized mice showed a significant higher production of all cytokines compared to those immunized with LL-pTREX1 and LL-pNZ8150, respectively $(P<0.0001)$. This finding indicates a mixed Th1/Th2 cell response. Mice immunized with purified EspB showed no significant increase in cytokine production compared to those received the BGM9 medium.

To determine the Th1/Th2 cell-type dominance, the IL-4/INF- $\gamma$ ratio was further analyzed for PP (Fig. 3B) and MLN (Fig. 3D) lymphocytes. The ratio in both LL-pNZ:SEC:EspB and LL-pT:SEC:EspB immunized mice was greater than one and was significantly higher than the baseline ratios shown by control mice immunized with the respective empty vector strain or with the BGM9 medium. This finding indicates a dominance of the Th2 response.

\subsection{Oral immunization with L. lactis-secreting EspB protects mice against E. coli 0157:H7 colonization}

Comparisons of E. coli 0157:H7 fecal counts among the immunization groups within either streptomycin-treated (Fig. 4A) or
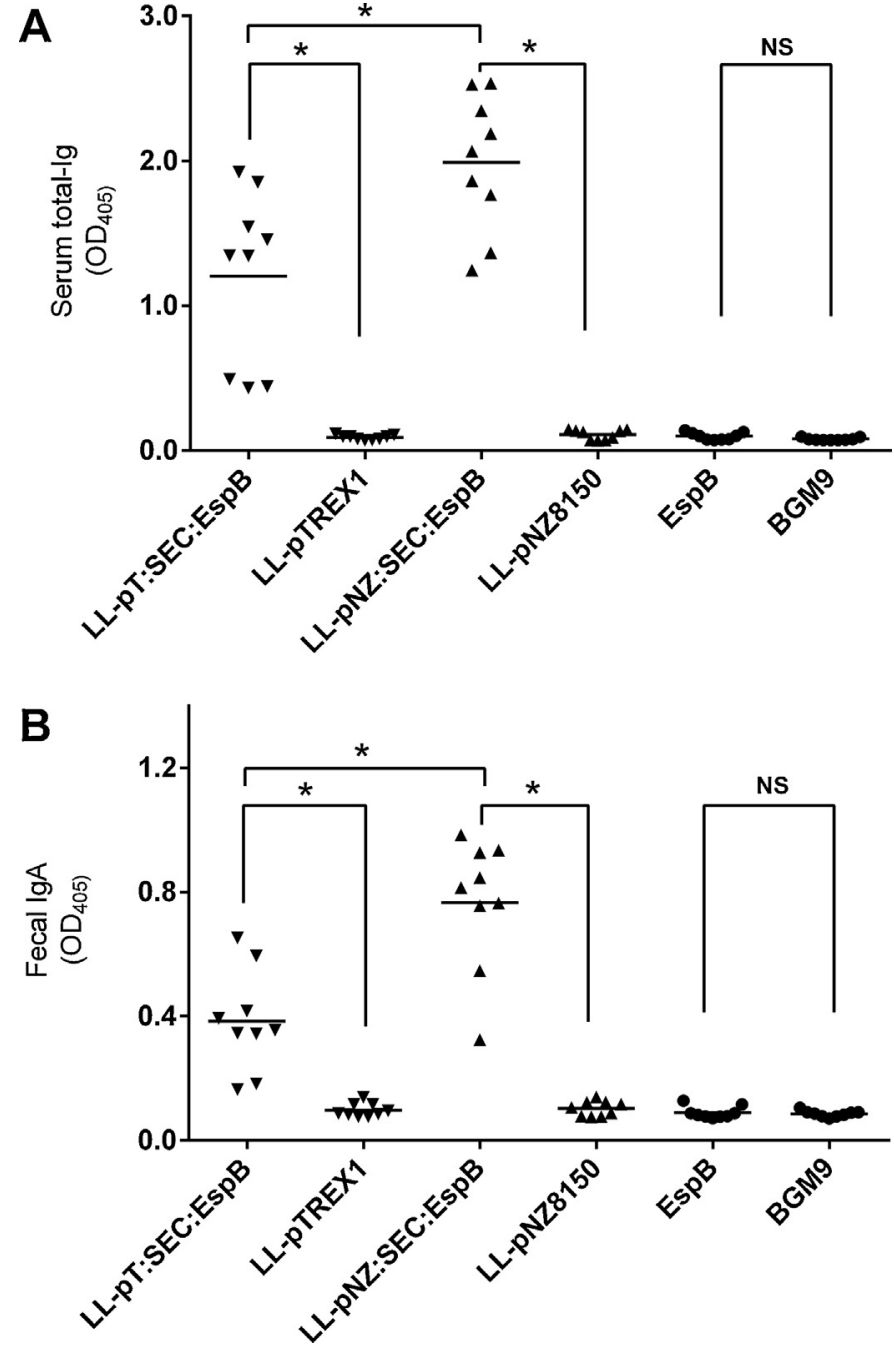

Fig. 2. Antibody responses in mice immunized with EspB-secreting lactococci. Groups of mice $(n=9)$ were immunized using the constitutive strain LL-pT:SEC:EspB, the inducible strain LL-pNZ:SEC:EspB or purified EspB. Corresponding control groups were immunized using LL-pTREX1, LL-pNZ8150 or the oral inoculation medium, BGM9. Ten days after the booster immunization serum and fecal samples were assayed by ELISA for the presence of EspB-specific total-Ig (A) or IgA (B), respectively. Data present individual values (triangles) and means (horizontal line) of nine mice per group. Statistical differences were determined using one-way ANOVA with Bonferroni post-hoc test $\left({ }^{*} P<0.0001\right.$; NS $=$ non significant difference).

non-streptomycin-treated (Fig. 4B) challenge groups show significantly reduced counts in LL-pNZ:SEC:EspB and LL-pT:SEC:EspB groups in comparison to LL-pNZ8150 and LL-pTREX1 groups, respectively, or to the BGM9 group, at most of the time points $(P<0.05)$. This reduction was significantly higher in the LL-pNZ:SEC:EspB immunization group compared to the LLpT:SEC:EspB group $(P<0.05)$ (Fig. 4 A and B).

Additionally, comparisons of the durations of E. coli 0157:H7 fecal shedding among the streptomycin-treated immunization groups show a significantly shorter duration in the LLpNZ:SEC:EspB group (11.52 \pm 2.87 days) compared to LL-pNZ8150 and BGM9 groups ( $30.5 \pm 1.73$ and $29.75 \pm 1.5$ days, respectively) $(P<0.05)$. However, the duration of fecal shedding shown by the LL-pT:SEC:EspB group was not significantly shorter than that of the LL-pTREX1 or the BGM9 group ( $26.75 \pm 1.5$ days versus $29.75 \pm 1.5$ days). Within the non-streptomycin-treated immunization groups, the duration of fecal shedding shown by the LL-pNZ:SEC:EspB group ( $11.52 \pm 2.87$ days) and the LL-pT:SEC:EspB group ( $16 \pm 1.73$ days) was significantly shorter than that of the LL-pNZ8150 group 
Table 2

ELISA quantification of EspB production by the recombinant L. lactis strains.

\begin{tabular}{|c|c|c|c|c|}
\hline \multirow[t]{2}{*}{ Strain } & \multirow[t]{2}{*}{ Expression features } & \multicolumn{3}{|c|}{ EspB expression in fractions of cultures $(\mu \mathrm{g} / \mathrm{ml})^{\dagger}$} \\
\hline & & Cell lysate & Supernatant & Total \\
\hline LL-pNZ:CYT:EspB & Nisin-inducible cytoplasmic & $0.082 \pm 0.02$ & $\mathrm{ND}^{*}$ & $0.082 \pm 0.02^{a}$ \\
\hline LL-pNZ:SEC:EspB & Nisin-inducible secretion & $0.83 \pm 0.19$ & $3.8 \pm 1.1$ & $4.63 \pm 1.29^{a}$ \\
\hline LL-pT:SEC:EspB & Constitutive secretion & $0.15 \pm 0.05$ & $1.9 \pm 0.4$ & $2.05 \pm 0.45^{\mathrm{a}}$ \\
\hline
\end{tabular}

$\dagger$ Culture density approximately equal to $8 \times 10^{8} \mathrm{CFU} / \mathrm{ml}$. Data represent means \pm standard deviation of three independent measurements

a Significant differences among the strains using one way-ANOVA with Bonferroni post-hoc test $(P<0.05)$.

ND: non detectable.

$(19.3 \pm 2.31$ days) and the LL-pTREX1 group (22 days), respectively or than that of the BGM9 group (22 days) $(P<0.05)$. The shorter duration of fecal shedding shown by the LL-pNZ:SEC:EspB group in comparison to the LL-pT:SEC:EspB group was significant $(P<0.05)$.

\section{Discussion}

We have recently reported the constitutive cytoplasmic expression of EspB in L. lactis (LL-pT:CYT:EspB) [23]. However, oral vaccination of BALB/c mice with this strain induced a weak priming the immune system [23]. This outcome was attributed to the low amount of EspB expressed by LL-pT:CYT:EspB, presumably due to the antigen degradation by the lactococcal cytoplasmic proteases [31-33]. Therefore, in the present study we hypothesized that secretion could allow EspB to escape cytoplasmic proteolysis and thus would result in a higher expression yield. Additionally, we compared a nisin-inducible and a constitutive expression system for the highest protein expression. In accordance with
A
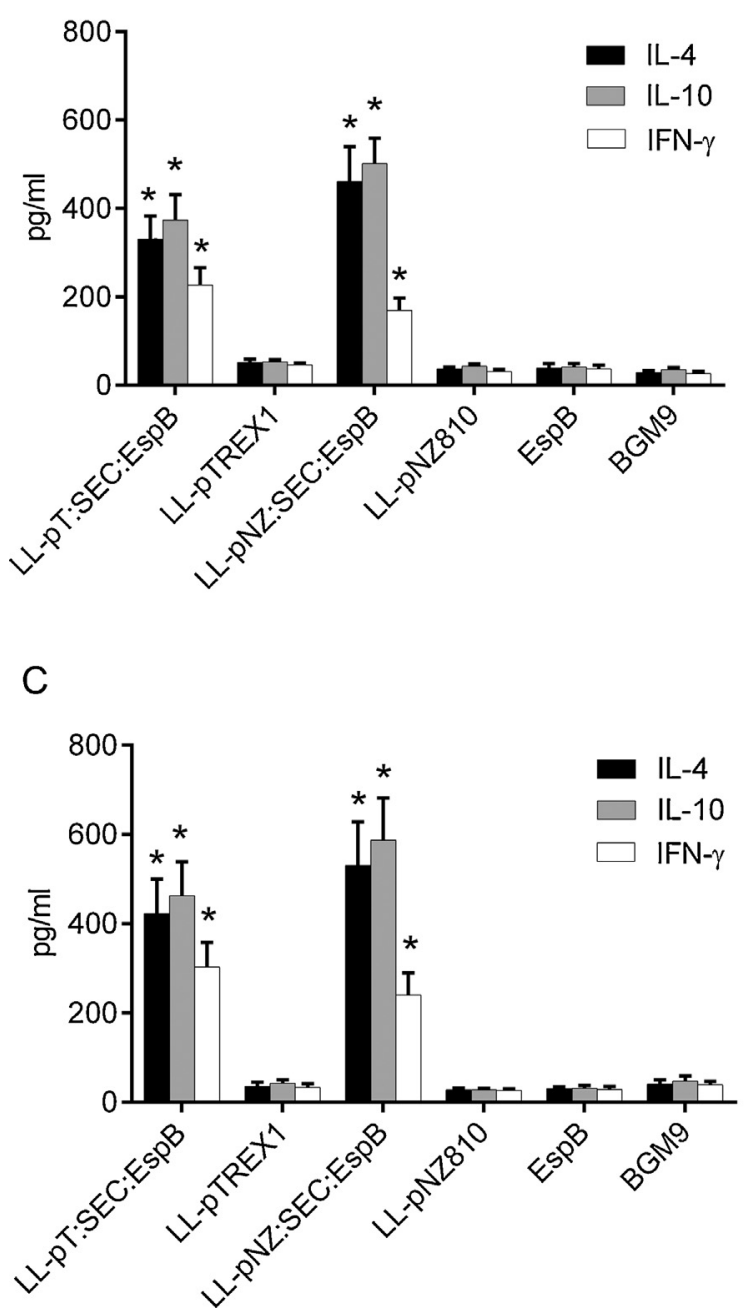

B

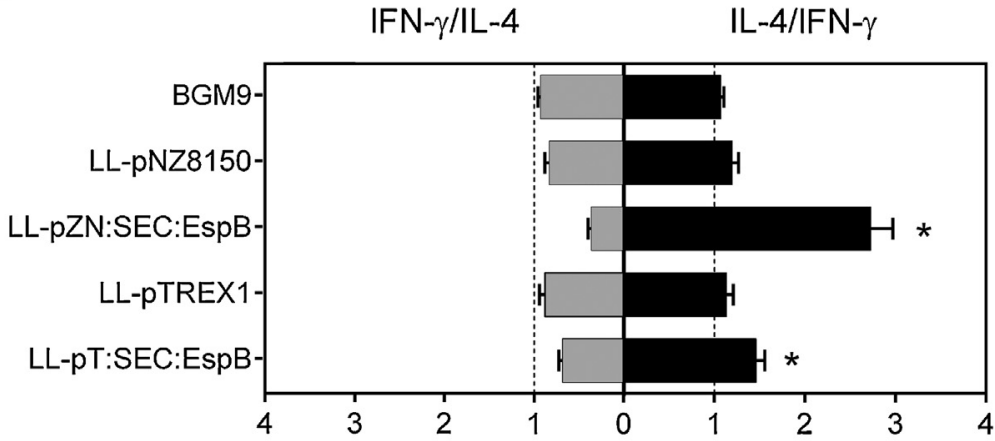

D

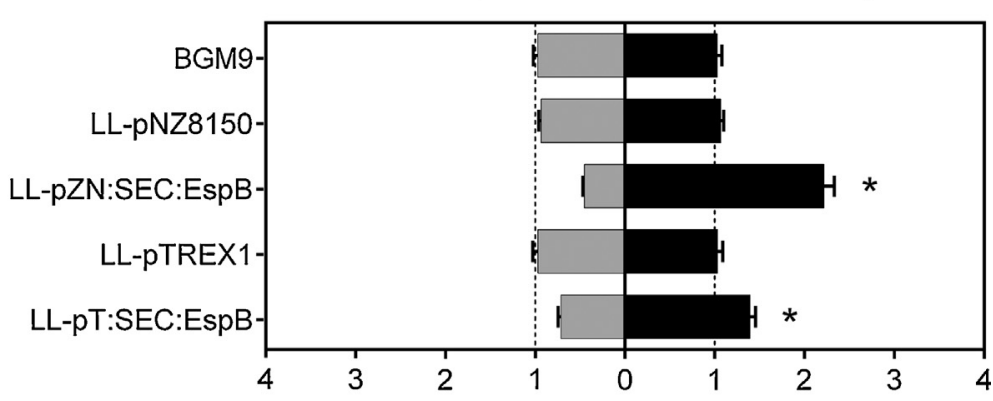

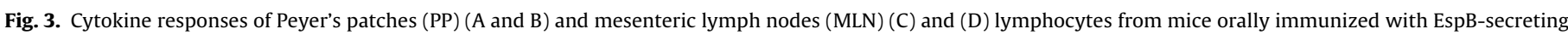

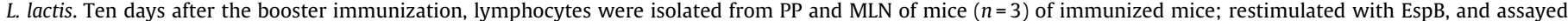

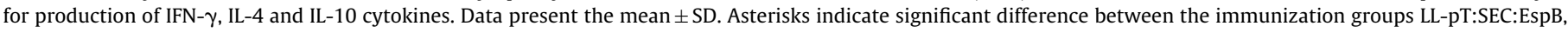

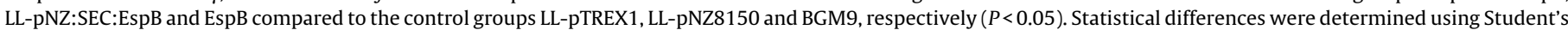

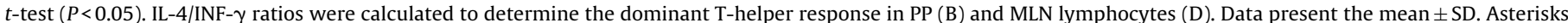

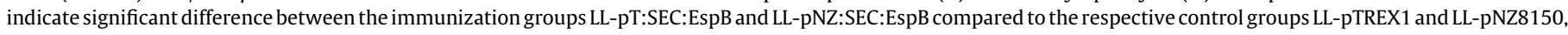
or to the BMG9 control group $(P<0.05)$. Statistical differences were determined using one-way ANOVA with Bonferroni post-hoc test $(P<0.05)$. 

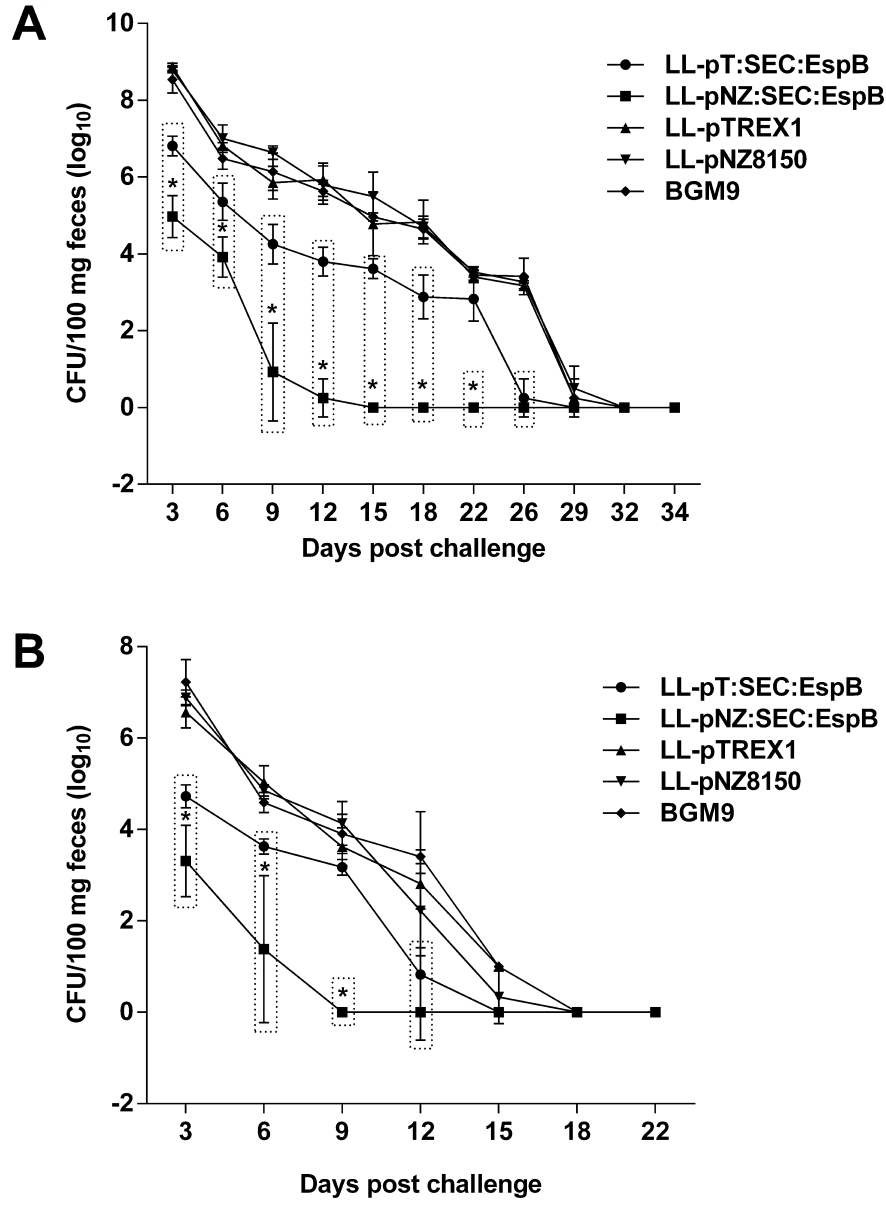

Fig. 4. Kinetics of fecal shedding of E. coli O157:H7 in mice immunized orally with EspB secreting lactococci. Ten days after the booster immunization, groups of immunized mice were orally challenged with $10^{10} \mathrm{CFU}$ of E. coli NCTC12900 (a non-toxigenic mutant of E. coli 0157:H7), either under oral streptomycin treatment condition $(n=4)(A)$ or without streptomycin treatment $(n=3)(B)$. Data present the mean \pm SD. Data points in rectangles indicate a significant difference between the LL-pT:SEC:EspB and pNZ:SEC:EspB immunization groups compared to the respective control groups LL-pTREX1 and LL-pNZ8150 or to the BGM9 control group $(P<0.05)$. Asterisks indicate statistical differences between the LL-pT:SEC:EspB and LL-pNZ:SEC:EspB immunization groups $(P<0.05)$. Data present the mean \pm SD. Statistical differences were determined using two-way ANOVA with Bonferroni post-hoc test $(P<0.05)$.

our hypothesis, secretion of EspB either under constitutive (LLpT:SEC:EspB) or inducible (LL-pNZ:SEC:EspB) conditions resulted in a great enhancement of the total antigen yield compared to the cytoplasmic expression by LL-pT:CYT:EspB (56- and 25-fold increase, respectively). A similar enhancement of the total protein yield by secretion in comparison to cytoplasmic expression has been reported for the expression of the staphylococcal nuclease [34] and the Brucella abortus ribosomal protein L7/L12 [35] in L. lactis.

The immune response induced by the EspB-secreting lactococci is expected to be influenced by EspB expression levels, which are at least two times higher for the nisin-inducible strain, LLpNZ:SEC:EspB compared to the constitutive strain, LL-pT:SEC:EspB. On the other hand, LL-pT:SEC:EspB is capable of constant secretion of EspB during the intestinal passage, which may compensate for the higher expression levels of LL-pNZ:SEC:EspB, whereas LLpNZ:SEC:EspB may not continue EspB secretion along the entire duration of its intestinal passage as nisin is absent in vivo. However, the highest immune responses were obtained by the inducible LL-pNZ:SEC:EspB strain. In this regard, previous reports have demonstrated the ability of nisin-inducible expression systems to continue protein expression for at least $10 \mathrm{~h}$ after removal of nisin from the culture medium [34]. Additionally, considering that the reported transit time of $L$. lactis throughout the mouse gastrointestinal tract is approximately $12 \mathrm{~h} \mathrm{[36],} \mathrm{it} \mathrm{is} \mathrm{highly} \mathrm{likely} \mathrm{that}$ both strains had a comparable persistence of EspB secretion in vivo, while the higher responses induced by LL-pNZ:SEC:EspB are a direct result of its higher capacity for EspB expression.

Unlike the mice immunized with the EspB-expressing L. lactis strains, those immunized with purified EspB did not show specific immune responses, even though EspB was given at a dose approximately equal to that present in the inoculum of LL-pT:SEC:EspB $(5 \mu \mathrm{g})$. This finding could be explained by the ability of $L$. lactis to maintain metabolic activity [37-39] and de novo secretion of recombinant proteins [38,39] during its gastrointestinal passage, leading to the delivery of higher amounts of EspB than those measured in the administered inocula [40]. Additionally, purified EspB could have been influenced by the degrading effects of the gastrointestinal acidity and enzymes, a bottleneck that can be overcome by using $L$. lactis as an antigen delivery vector. Moreover, $L$. lactis exhibits adjuvant effects [41], which can enhance the immune response to recombinant $\mathrm{EspB}$ in comparison to the purified protein [42-44]. These arguments support the pharmacological and the immunological value of $L$. lactis as an oral antigen delivery system [45-47].

To characterize the cellular immune responses induced by oral immunization of mice with the EspB-secreting strains, we isolated lymphocytes from PP and MLN, the main inductive sites of the gut mucosal immune system [48] and measured the production of INF$\gamma$ (Th1 cytokine) and IL-4 (Th2 cytokine) [29]after stimulating the cells with EspB in vitro. Both cytokines were produced by lymphocytes of immunized mice, indicating the induction of a mixed Th1/Th2 cell response. Previous reports have similarly described a mixed Th1/Th2 cell response to antigens orally delivered by L. lactis $[46,49,50]$. Additionally, analysis of the IL-4:INF- $\gamma$ ratio's indicated a dominance of the Th2 response, which is a typical characteristic of an intestinal mucosal response $[29,46]$. The Th2 dominance corresponds well with the induced mucosal IgA responses, since Th2 cells and cytokines are known to contribute to mucosal IgA class switching in PP and MLN [51,52].

Reduced intestinal colonization is considered an important criterion for protection against EHEC virulence [53,54]. Our findings show that oral immunization of mice with the EspB-secreting $L$. lactis strains resulted in a reduction of E. coli $0157: \mathrm{H} 7$ fecal shedding. Moreover, the reduced bacterial shedding was consistent in two infection models of varying colonization intensities indicating the efficacy and the reproducibility of our vaccination approach. This pattern of protection could be correlated with an intestinal EspB-specific IgA response, which is consistent with the protective role of secretory IgA in mucosal infections [18]. However, previous immunization studies in mice models, particularly those involving T3SS antigens, lack consensus on the necessity of intestinal IgA responses for clearing an EHEC infection (recently reviewed in [55]). For instance, intramuscular immunization with a mixture of T3SS proteins eliminated EHEC shedding, despite the absence of fecal Tir- or EspA-specific IgA responses [56]. On the other hand, a subcutaneous immunization with Tir failed to induce intestinal IgA responses and to protect mice against a challenge [57]. With regard to EspB, previous reports have described the protective effect of parenteral vaccination with formulations containing EspB $[58,59]$. However, these studies were performed in cattle, a species in which IgG responses contribute largely to intestinal mucosal protection [60]. The present study, however, is the first to describe the protective potential of EspB upon oral vaccination.

In conclusion, oral immunization of mice with recombinant L. lactis secreting EspB induces specific mucosal and systemic immune responses and confers protection against an $E$. coli 
0157:H7 challenge infection. These findings demonstrate the feasibility of an oral vaccine based on the recombinant expression of EspB in L. lactis to control EHEC infection. The safety profile of $L$. lactis as a vaccine delivery vector can particularly be beneficial to children and elderly, the high-risk groups for HUS complications [1].

\section{Author contribution statement}

All authors have substantially contributed to the study design, the acquisition, analysis and interpretation of the data, the manuscript drafting and the revision of its intellectual contents. All authors have approved the submitted manuscript.

\section{Acknowledgments}

This work was supported by the Special Research Fund (BOF) of Ghent University and the (project G0A4312N) and FOD health, food chain safety and environment. We gratefully acknowledge Dr. Erik Remaut, Department of Biomedical Molecular Biology, Ghent University, for providing the strain L. lactis GM1363 as well as the lactococcal expression vector, pTREX1. We also gratefully acknowledge Pieter Almgren, for his technical help.

Conflict of interest statement: The authors declare no conflicts of interest with respect to authorship, funding and publication of this article.

\section{References}

[1] Griffin PM, Tauxe RV. The epidemiology of infections caused by Escherichia coli 0157:H7, other enterohemorrhagic E. coli, and the associated hemolytic uremic syndrome. Epidemiol Rev 1991;13:60-98.

[2] Trachtman H, Cnaan A, Christen E, Gibbs K, Zhao S, Acheson DW, et al. Effect of an oral Shiga toxin-binding agent on diarrhea-associated hemolytic uremic syndrome in children: a randomized controlled trial. JAMA 2003;290:1337-44 (the journal of the American Medical Association).

[3] Carter AO, Borczyk AA, Carlson JA, Harvey B, Hockin JC, Karmali MA, et al. A severe outbreak of Escherichia coli 0157:H7-associated hemorrhagic colitis in a nursing home. N Engl J Med 1987;317:1496-500.

[4] Serna A, Boedeker EC. Pathogenesis and treatment of Shiga toxin-producing Escherichia coli infections. Curr Opin Gastroenterol 2008;24:38-47.

[5] Pavia AT, Nichols CR, Green DP, Tauxe RV, Mottice S, Greene KD, et al. Hemolytic-uremic syndrome during an outbreak of Escherichia coli 0157:H7 infections in institutions for mentally retarded persons: clinical and epidemiologic observations. J Pediatr 1990;116:544-51.

[6] Wong CS, Jelacic S, Habeeb RL, Watkins SL, Tarr PI. The risk of the hemolytic-uremic syndrome after antibiotic treatment of Escherichia coli O157:H7 infections. N Engl J Med 2000;342:1930-6.

[7] Wong CS, Mooney JC, Brandt JR, Staples AO, Jelacic S, Boster DR, et al. Risk factors for the hemolytic uremic syndrome in children infected with Escherichia coli 0157:H7: a multivariable analysis. Clin Infect Dis 2012;55:33-41.

[8] Hamada D. Cytoskeleton-modulating effectors of enteropathogenic and enterohemorrhagic Escherichia coli. FEBS J 2010;277:2389.

[9] Frankel G, Phillips AD, Rosenshine I, Dougan G, Kaper JB, Knutton S. Enteropathogenic and enterohaemorrhagic Escherichia coli: more subversive elements. Microbiol Biotechnol 1998;30:911-21.

[10] Kodama T, Akeda Y, Kono G, Takahashi A, Imura K, Iida T, et al. The EspB protein of enterohaemorrhagic Escherichia coli interacts directly with alpha-catenin. Cell Microbiol 2002;4:213-22.

[11] Knappstein S, Ide T, Schmidt MA, Heusipp G. Alpha 1-antitrypsin binds to and interferes with functionality of $\operatorname{EspB}$ from atypical and typical enteropathogenic Escherichia coli strains. Infect Immun 2004;72:4344-50.

[12] Iizumi Y, Sagara H, Kabe Y, Azuma M, Kume K, Ogawa M, et al. The enteropathogenic E. coli effector EspB facilitates microvillus effacing and antiphagocytosis by inhibiting myosin function. Cell Host Microbe 2007;2:383-92

[13] Asper DJ, Karmali MA, Townsend H, Rogan D, Potter AA. Serological response of Shiga toxin-producing Escherichia coli type III secreted proteins in sera from vaccinated rabbits, naturally infected cattle, and humans. Clin Vaccine Immunol: CVI 2011;18:1052-7.

[14] Li Y, Frey E, Mackenzie AM, Finlay BB. Human response to Escherichia coli 0157:H7 infection: antibodies to secreted virulence factors. Infect Immun 2000;68:5090-5.

[15] Karpman D, Bekassy ZD, Sjogren AC, Dubois MS, Karmali MA, Mascarenhas M, et al. Antibodies to intimin and Escherichia coli secreted proteins A and B in patients with enterohemorrhagic Escherichia coli infections. Pediatr Nephrol 2002;17:201-11.
[16] Cataldi A, Yevsa T, Vilte DA, Schulze K, Castro-Parodi M, Larzabal M, et al. Efficient immune responses against Intimin and EspB of enterohaemorragic Escherichia coli after intranasal vaccination using the TLR2/6 agonist MALP-2 as adjuvant. Vaccine 2008;26:5662-7.

[17] Neutra MR, Kozlowski PA. Mucosal vaccines: the promise and the challenge. Nat Rev Immunol 2006;6:148-58.

[18] Pavot V, Rochereau N, Genin C, Verrier B, Paul S. New insights in mucosal vaccine development. Vaccine 2012;30:142-54.

[19] Lycke N. Recent progress in mucosal vaccine development: potential and limitations. Nat Rev Immunol 2012;12:592-605

[20] Berlec A, Ravnikar M, Strukelj B. Lactic acid bacteria as oral delivery systems for biomolecules. Pharmazie 2012;67:891-8.

[21] Tarahomjoo S. Development of vaccine delivery vehicles based on lactic acid bacteria. Mol Biotechnol 2012;51:183-99.

[22] Wells J. Mucosal vaccination and therapy with genetically modified lactic acid bacteria. Annu Rev Food Sci Technol 2011;2:423-45.

[23] Ahmed B, Loos M, Vanrompay D, Cox E. Mucosal priming of the murine immune system against enterohemorrhagic Escherichia coli 0157:H7 using Lactococcus lactis expressing the type III secretion system protein EspB. Vet Immunol Immunopathol 2013;152:141-5.

[24] Wells JM, Wilson PW, Lepage RWF. Improved cloning vectors and transformation procedure for Lactococcus lactis. I Appl Bacteriol 1993;74: 629-36.

[25] Schotte L, Steidler L, Vandekerckhove J, Remaut E. Secretion of biologically active murine interleukin-10 by Lactococcus lactis. Enzyme Microb Technol 2000;27:761-5.

[26] Sebastiani S, Allavena P, Albanesi C, Nasorri F, Bianchi G, Traidl C, et al Chemokine receptor expression and function in CD4(+) T lymphocytes with regulatory activity. J Immunol 2001;166:996-1002.

[27] Wadolkowski EA, Burris JA, Obrien AD. Mouse model for colonization and disease caused by enterohemorrhagic Escherichia coli 0157-H7. Infect Immun 1990:58:2438-45.

[28] Vandewalle K, Atefyekta M, Verdonck F, De Zutter L, Cox E. Rectal inoculation of sheep with E. coli 0157:H7 results in persistent infection in the absence of a protective immune response. Vet Microbiol 2011;147:376-82.

[29] Neurath MF, Finotto S, Glimcher LH. The role of Th1/Th2 polarization in mucosal immunity. Nat Med 2002;8:567-73.

[30] Saraiva M, O'Garra A. The regulation of IL-10 production by immune cells. Nat Rev Immunol 2010;10:170-81.

[31] Frees D, Ingmer H. ClpP participates in the degradation of misfolded protein in Lactococcus lactis. Microbiol Biotechnol 1999;31:79-87.

[32] Nilsson D, Lauridsen AA, Tomoyasu T, Ogura T. A Lactococcus lactis gene encodes a membrane-protein with putative ATPase activity that is homologous to the essential Escherichia coli Ftsh gene-product. Microbiology-UK 1994; $140: 2601-10$

[33] Koch B, Kilstrup M, Vogensen FK, Hammer K. Induced levels of heat shock proteins in a DNAK mutant of Lactococcus lactis. J Bacteriol 1998;180: 3873-81.

[34] Bermudez-Humaran LG, Langella P. Commissaire J, Gilbert S, Le Loir Y, L'Haridon $\mathrm{R}$, et al. Controlled intra- or extracellular production of staphylococcal nuclease and ovine omega interferon in Lactococcus lactis. FEMS Microbiol Lett 2003;224:307-13.

[35] Ribeiro LA, Azevedo V, Le Loir Y Oliveira SC, Dieye Y, Piard JC, et al Production and targeting of the Brucella abortus antigen L7/L12 in Lactococcus lactis: a first step towards food-grade live vaccines against brucellosis. Appl Environ Microbiol 2002;68:910-6.

[36] Kimoto H, Nomura M, Kobayashi M, Mizumachi K, Okamoto T. Survival of lactococci during passage through mouse digestive tract. Can J Microbiol 2003;49:707-11.

[37] Drouault S, Corthier G, Ehrlich SD, Renault P. Survival, physiology, and lysis of Lactococcus lactis in the digestive tract. Appl Environ Microbiol 1999;65:4881-6

[38] Steidler L, Hans W, Schotte L, Neirynck S, Obermeier F, Falk W, et al. Treatment of murine colitis by Lactococcus lactis secreting interleukin-10. Science 2000;289:1352-5

[39] Huibregtse IL, Snoeck V, de Creus A, Braat H, De Jong EC, Van Deventer SJ, et al. Induction of ovalbumin-specific tolerance by oral administration of Lactococcus lactis secreting ovalbumin. Gastroenterology 2007;133:517-28.

[40] Hou J, Lu Y, Liu HY, Ma YJ, Xing Y, Zhang Y, et al. Oral administration of Lactococcus lactis delivered heat shock protein 65 attenuates atherosclerosis in low-density lipoprotein receptor-deficient mice. Vaccine 2011;29: 4102-9.

[41] Yam KK, Pouliot P, N’Diaye MM, Fournier S, Olivier M, Cousineau B. Innate inflammatory responses to the Gram-positive bacterium Lactococcus lactis. Vaccine 2008;26:2689-99.

[42] Chatel JM, Langella P, Adel-Patient K, Commissaire J, Wal JM, Corthier G. Induction of mucosal immune response after intranasal or oral inoculation of mice with Lactococcus lactis producing bovine beta-lactoglobulin. Clin Diagn Lab Immunol 2001;8:545-51.

[43] Marelli B, Perez AR, Banchio C, de Mendoza D, Magni C. Oral immunization with live Lactococcus lactis expressing rotavirus VP8* subunit induces specific immune response in mice. J Virol Methods 2011;175:28-37.

[44] Adel-Patient K, Ah-Leung S, Creminon C, Nouaille S, Chatel JM, Langella P, et al. Oral administration of recombinant Lactococcus lactis expressing bovine beta-lactoglobulin partially prevents mice from sensitization. Clin Exp Allergy 2005;35:539-46. 
[45] Saez D, Fernandez P, Rivera A, Andrews E, Onate A. Oral immunization of mice with recombinant Lactococcus lactis expressing $\mathrm{Cu}$, Zn superoxide dismutase of Brucella abortus triggers protective immunity. Vaccine 2012;30: 1283-90.

[46] Robinson K, Chamberlain LM, Schofield KM, Wells JM, Le Page RW. Oral vaccination of mice against tetanus with recombinant Lactococcus lactis. Nat Biotechnol 1997; 15:653-7.

[47] Cho HJ, Shin HJ, Han IK, Jung WW, Kim YB, Sul D, et al. Induction of mucosal and systemic immune responses following oral immunization of mice with Lactococcus lactis expressing human papillomavirus type 16 L1. Vaccine 2007:25:8049-57.

[48] Pabst R, Rothkotter HJ. Structure and function of the gut mucosal immune system. Adv Exp Med Biol 2006;579:1-14.

[49] Cauchard S, Bermudez-Humaran LG, Blugeon S, Laugier C, Langella P, Cauchard J. Mucosal co-immunization of mice with recombinant lactococci secreting VapA antigen and leptin elicits a protective immune response against Rhodococcus equi infection. Vaccine 2011;30:95-102

[50] Villena J, Medina M, Raya R, Alvarez S. Oral immunization with recombinant Lactococcus lactis confers protection against respiratory pneumococcal infection. Can J Microbiol 2008;54:845-53.

[51] Yamamoto M, Vancott JL, Okahashi N, Marinaro M, Kiyono H, Fujihashi K, et al. The role of Th1 and Th2 cells for mucosal IgA responses. Ann NY Acad Sci 1996;778:64-71.

[52] Okahashi N, Yamamoto M, Vancott JL, Chatfield SN, Roberts M, Bluethmann H, et al. Oral immunization of interleukin-4 (IL-4) knockout mice with a recombinant Salmonella strain or cholera toxin reveals that CD4(+) Th2 cells producing IL-6 and IL-10 are associated with mucosal immunoglobulin a responses. Infect Immun 1996;64:1516-25.

[53] Oliveira AF, Cardoso SA, Almeida FBD, de Oliveira LL, Pitondo-Silva A Soares SG, et al. Oral immunization with attenuated Salmonella vaccine expressing Escherichia coli 0157:H7 intimin gamma triggers both systemic and mucosal humoral immunity in mice. Microbiol Immunol 2012;56: 513-22.
[54] Judge NA, Mason HS, O’Brien AD. Plant cell-based intimin vaccine given orally to mice primed with intimin reduces time of Escherichia coli 0157:H7 shedding in feces. Infect Immun 2004;72:168-75.

[55] Garcia-Angulo VA, Kalita A, Torres AG. Advances in the development of enterohemorrhagic Escherichia coli vaccines using murine models of infection. Vaccine 2013;31:3229-35.

[56] Babiuk S, Asper DJ, Rogan D, Mutwiri GK, Potter AA. Subcutaneous and intranasal immunization with type III secreted proteins can prevent colonization and shedding of Escherichia coli 0157:H7 in mice. Microb Pathog 2008;45:7-11.

[57] Fan HY, Wang L, Luo J, Long BG. Protection against Escherichia coli 0157:H7 challenge by immunization of mice with purified Tir proteins. Mol Biol Rep 2012;39:989-97.

[58] Vilte DA, Larzabal M, Garbaccio S, Gammella M, Rabinovitz BC, Elizondo AM, et al. Reduced faecal shedding of Escherichia coli 0157:H7 in cattle following systemic vaccination with gamma-intimin C-280 and EspB proteins. Vaccine 2011;29:3962-8.

[59] Atefyekta M, Goddeeris BM, Vanrompay D, Cox E. Immunization of sheep with a combination of intimin gamma, EspA and EspB decreases Escherichia coli 0157:H7 shedding. Vet Immunol Immunopathol 2011;140:42-6.

[60] Bailey M. The immune system: differences between man, pigs, ruminants and mice. Front Immunol 2011, http://dx.doi.org/10.3389/conf.fimmu. 2011.01.00003.

[61] Gasson MJ. Plasmid complements of Streptococcus lactis NCDO 712 and other lactic streptococci after protoplast-induced curing. J Bacteriol 1983;154:1-9.

[62] Kuipers OP, de Ruyter PGGA, Kleerebezem M, de Vos WM. Quorum sensingcontrolled gene expression in lactic acid bacteria. J Biotechnol 1998;64:15-21.

[63] Woodward MJ, Best A, Sprigings KA, Pearson GR, Skuse AM, Wales A, et al. Nontoxigenic Escherichia coli 0157:H7 strain NCTC12900 causes attaching-effacing lesions and eae-dependent persistence in weaned sheep. Int J Med Microbiol 2003:293:299-308.

[64] Mierau I, Kleerebezem M. 10 years of the nisin-controlled gene expression system (NICE) in Lactococcus lactis. Appl Microbiol Biotechnol 2005;68:705-17. 